Int. J. Electrochem. Sci., 15 (2020) $7093-7105$

International Journal of

ELECTROCHEMICAL

SCIENCE

www.electrochemsci.org

\title{
Substrate pretreatment using plasma etching to enhance electroless Ni-P coatings performance
}

\author{
Hua Huang ${ }^{1}$, Ming-Chang Wu ${ }^{2}$, Tao Liang ${ }^{3}$, Ding-Yeng Chen ${ }^{4}$,Chung-Chen Tsao ${ }^{2, *}$, Chun-Yao Hsu ${ }^{2 *}$ \\ ${ }^{1}$ Department of Marine Engineering, Zhejiang International Maritime College, Zhoushan 316021 , \\ China \\ ${ }^{2}$ Department of Mechanical Engineering, Lunghwa University of Science and Technology, Taoyuan \\ 33306, Taiwan \\ ${ }^{3}$ Department of Mechanical Engineering, Dongguan University of Technology, Dongguan 523015, \\ China \\ ${ }^{4}$ Department of Mechanical Engineering, Hwa Hsia University of Technology, New Taipei City \\ 23568, Taiwan \\ "E-mail: aetcc@ mail.lhu.edu.tw (C. C. Tsao), cyhsu@ mail.lhu.edu.tw (C. Y. Hsu)
}

doi: $10.20964 / 2020.07 .93$

Received: 7 February 2020 / Accepted: 5 March 2020 / Published: 10 June 2020

Traditional electroless $\mathrm{Ni}-\mathrm{P}$ films are produced using a substrate pretreatment (sensitization and activation) and chemical plating. The Taguchi method is used to determine the optimal coating parameters for electroless $\mathrm{Ni}-\mathrm{P}$ films to achieve the best hardness and resistance to fatigue. The films are characterized using X-ray diffraction, scanning electron microscopy, by determining the fatigue life and using a nanoindenter. Analysis of variance results for the fatigue life for $\mathrm{Ni}-\mathrm{P}$ films, the deposition time, the bath temperature and the $\mathrm{pH}$ value of the solution have respective contributions of $64.61 \%$, $19.34 \%$ and $13.17 \%$. In the confirmation tests, the respective values for fatigue life and the films' hardness increase from 42.25 times and 548.9 HV to 47.67 times and 572.4 HV. This study replaces a traditional substrate pretreatment with oxygen plasma etching. Oxygen plasma etching changes the morphology of the substrate's surface, increases the surface free energy and produces slight pitting and micro roughness to give a surface that is more hydrophilic. Substrates that undergo pretreatment using oxygen plasma etching have enhanced mechanical properties because a relatively good $\mathrm{Ni}-\mathrm{P}$ film is produced. The results show that the fatigue life is increased from 47.67 times to 63.33 times and the NiP film's hardness is increased from 572.4 HV to $623.8 \mathrm{HV}$.

Keywords: electroless plating, Taguchi methodology, oxygen plasma etching, mechanical property. 
(C) 2020 The Authors. Published by ESG (www.electrochemsci.org). This article is an open access article distributed under the terms and conditions of the Creative Commons Attribution license (http://creativecommons.org/licenses/by/4.0/). 